\title{
Detection of antibodies against Leishmania infantum in cats (Felis catus) from the State of Pernambuco, Brazil
}

\author{
Rita de Cássia Nascimento Silva ${ }^{[1]}$, Rafael Antonio Nascimento Ramos ${ }^{[1],[2],}$ \\ Danillo de Souza Pimentel ${ }^{[1]}$, Gênova Maria de Azevedo Oliveira ${ }^{[3]}$, \\ Gílcia Aparecida de Carvalho ${ }^{[4]}$, Marília de Andrade Santana ${ }^{[1]}$, \\ Maria Aparecida da Glória Faustino ${ }^{[1]}$ and Leucio Câmara Alves ${ }^{[1]}$
}

[1]. Laboratório de Doenças Parasitárias dos Animais Domésticos, Universidade Federal Rural de Pernambuco, Recife, PE. [2]. Dipartimento di Medicina Veterinária, Università degli Studi di Bari, Valenzano, BA, Italy. [3]. Secretaria Estadual de Saúde de Pernambuco, Recife, PE. [4]. Unidade Acadêmica de Garanhuns, Universidade Federal Rural de Pernambuco, Garanhuns, PE.

\begin{abstract}
Introduction: Little information is available concerning infection by Leishmania infantum in cats. Therefore, the aim of this study was to perform a serological study in domestic cats. Methods: Serum samples $(\mathrm{n}=153)$ obtained from animals living in the Cities of Recife and Petrolina, State of Pernambuco, Brazil, were tested by ELISA $/ S 7^{\circledR}$ (Biogene). Results: Anti-L. infantum antibodies were detected in 3.9\% (6/153) of the cats. All seroreagent animals were from Petrolina. Conclusions: These results serve as an important alert, and future studies are needed to better understand the possible role of cats in the epidemiology of visceral leishmaniasis (VL) in this area.
\end{abstract}

Keywords: Feline. Antibody. Leishmania.

Visceral leishmaniasis (VL) is a protozoan disease caused by Leishmania infantum, which affects several species of animals, including humans. The reservoirs for this parasite can include wild and domestic mammals, with domestic dogs serving as the most important reservoir in Brazil, where the disease is present in urban areas ${ }^{1}$. Infections in other pet animals, such as cats, have also been reported, mainly in certain European countries ${ }^{2}$ as well as Brazil ${ }^{3}$. Although the role of cats in the epidemiology of VL has not been fully elucidated, data obtained from various studies suggest that this animal may act as secondary reservoirs or simply as accidental hosts.

For example, an experimental study in Italy demonstrated the natural infection of Phlebotomus perniciosus by $L$. infantum in a $\mathrm{cat}^{4}$. In Brazil, the presence of $L$. infantum promastigotes in the midgut of Lutzomyia longipalpis, as demonstrated by xenodiagnosis, recently confirmed the presence of parasites in the skin of a cat, suggesting the ability of this animal to act as a source of infection.

Considering that VL remains a large threat to public health in Brazil, and notably in Pernambuco, studies on infection by L. infantum in animals from urban areas are needed, even though the epidemiological role of other vertebrate species is not completely clear. Therefore, the aim of this study was to conduct a serological study on domestic cats from an area in Brazil endemic for VL.

\footnotetext{
Address to: Dr. Leucio Câmara Alves. Lab de Doenças Parasitárias dos Animais Domésticos/UFRPE. Av. Dom Manoel de Medeiros s/n, Dois Irmãos, 52171900 Recife, PE, Brasil.

Phone: $55813320-6422$

e-mail: leucioalves@gmail.com

Received in 17 September 2013

Accepted in 01 March 2013
}

From May to June of 2010, blood convenience samples $(\mathrm{n}=153)$ from cats of different ages and breeds were collected by venipuncture. In total, 48 animals lived in a private animal shelter in Recife (Latitude: 8 ${ }^{\circ} 3^{\prime} 15^{\prime \prime}$ South, Longitude: $34^{\circ} 52^{\prime} 53^{\prime \prime}$ West), and 105 animals were domiciled cats from Petrolina (Latitude: $9^{\circ} 23^{\prime} 39^{\prime \prime}$ South, Longitude: $40^{\circ} 30^{\prime} 35^{\prime \prime}$ West), both located in the State of Pernambuco. The obtained sera were stored at $-20^{\circ} \mathrm{C}$ until serological analysis. At admission, all animals were submitted to a clinical exam, and the data collected were recorded on a clinical chart.

The serological analyses were performed using an enzymelinked immunosorbent assay (ELISA) $\left(\mathrm{S} 7^{\circledR}\right.$ Biogene) based on a recombinant peptide, according to the manufacturer's instructions. The samples were tested in duplicate, including blank, negative, and positive controls. The positive and negative control sera were provided in the ELISA kit.

In this study, the sera from 153 cats $(77$ males and 76 females) were analyzed by ELISA, and we detected antiL. infantum antibodies in 3.9\% (6/153) of the cats. All positive animals were from Petrolina. Among the positive animals, $50 \%(3 / 6)$ were male, and $50 \%(3 / 6)$ were female. Regarding the age, $33.3 \%$ (2/6) were between 6 and 12 months of age, $33.3 \%$ (2/6) were between 12 months and 3 years, and $33.3 \%(2 / 6)$ were more than 3 years. At the clinical exam, the presence of cutaneous lesions was observed in $2.6 \%$ (4/153) of the animals, 2 of which were seroreagent by ELISA.

This study detected the presence of anti- $L$. infantum antibodies in cats from Pernambuco, with a positive rate of $3.9 \%(6 / 153)$. Seroreagent animals were restricted to a single City (i.e., Petrolina), and all serum samples obtained in Recife were not seroreagent. This difference may be the result of a 
series of factors, although two explanations are most likely. First, the biological vector of $L$. infantum is considered absent in Recife $^{6}$, and second, Petrolina is located in an endemic area with favorable conditions for the development of vectors, showing a seroprevalence in dogs of $19.1 \%(115 / 600)^{7}$ and the presence of human cases. It is also important to consider the conditions in which these animals lived; the animals from Recife were confined to a private shelter, whereas the domiciled cats from Petrolina had contact with other animals and environments, and theoretically received greater exposure to VL vectors. Although it was not possible to detect seroreagent animals from Recife, it is important to highlight that cases of VL have been detected in dogs and humans in the metropolitan region of Recife ${ }^{8}$, which is an area considered endemic for VL.

Although the first case of feline leishmaniasis was described in $1912^{9}$, little is known about this infection in cats. There are few seroprevalence studies as well as limited parasitological and molecular evidence of the presence of Leishmania parasites in these animals. Several studies have reported a seroprevalence ranging from $0.9 \%$ to $6.7 \%$ in Europe ${ }^{10,11}$, whereas in Brazil, Silveira Neto et al. ${ }^{3}$ reported a prevalence ranging from $13.3 \%$ to $23 \%$.

The low number of seroreagent animals obtained in the present study may have been due to the use of a single serological test, as previous data have demonstrated that the serological test used in this study (i.e., the ELISA $/ S 7^{\circledR}$ ) presents greater sensitivity when used together with other serological tests $^{12}$. The host immune response, vector preference, the natural resistance of the cat ${ }^{13}$, and reduced body area exposure to the vector (considering the fur density present on cats) could also explain the low number of seropositive animals.

Among the positive animals reported in this study, cutaneous lesions were reported in two cats. Unfortunately, biopsies of the lesions presented by these animals were not performed because the owners did not give permission.

The true potential for cats to be infected by L. infantum remains poorly characterized ${ }^{14}$, and the lower level of antibodies and the absence of clinical signs presented by infected animals may explain the underestimated number of positive animals, especially when compared to studies in $\operatorname{dog} \mathrm{s}^{15}$. Moreover, it is important to assess infection by vectors that feed on $L$. infantumpositive cats $^{4,5}$. The present study was the first serological study performed on cats from Pernambuco. Although the role of the cat as a source of infection by $L$. infantum has not been completely elucidated, the data described here suggest that these animals come into contact with the protozoa. However, further studies are needed to characterize this potential infection and understand whether cats affect the epidemiology of VL in the studied area.

\section{ACKNOWLEDGMENTS}

The authors wish to thank the Biogene Indústria e Comércio Ltda ME, which supplied the ELISA test, and the Secretaria de Saúde do Estado de Pernambuco, which partially contributed to the realization of this study.

\section{CONFLICT OF INTEREST}

The authors declare that there is no conflict of interest.

\section{REFERENCES}

1. Silva ES, Gontijo CM, Pacheco RS, Fiuza VO, Brazil RP. Visceral leishmaniasis in the Metropolitan Region of Belo Horizonte, State of Minas Gerais, Brazil. Mem Inst Oswaldo Cruz 2001; 96:285-291.

2. Solano-Gallego L, Rodríguez-Cortés A, Iniesta L, Quintana J, Pastor J, Espada Y, et al. Cross-sectional serosurvey of feline leishmaniasis in ecoregions around the Northwestern Mediterranean. Am J Trop Med Hyg 2007; 76:676-680.

3. Silveira Neto L, Vicente Sobrinho LS, Martin CO, Machado RZ, Marcondes M, Lima MMF. Use of crude, FML and rK39 antigens in ELISA to detect anti-Leishmania spp. antibodies in Felis catus. Vet Parasitol 2011; 177 : 374-377.

4. Maroli M, Pennisi MG, Di Muccio T, Khoury C, Gradoni L, Gramiccia M. Infection of sandflies by a cat naturally infected with Leishmania infantum. Vet Parasitol 2007; 145:357-360.

5. Silva SM, Rabelo PFB, Gontijo NF, Ribeiro RR, Melo MN, Ribeiro VM, Michalick MSM. First report of infection of Lutzomyia longipalpis by Leishmania (Leishmania) infantum from a naturally infected cat of Brazil. Vet Parasitol 2010; 174:150-154.

6. Dantas-Torres F, Faustino MAG, Lima OC, Acioli RV. Epidemiologic surveillance of canine visceral leishmaniasis in the municipality of Recife, Pernambuco. Rev Soc Bras Med Trop 2005; 38:444-445.

7. Pimentel DS. Distribuição espacial da Leishmaniose Visceral Canina no município de Petrolina, Estado de Pernambuco, Brasil. [Thesis]. [Recife]: Universidade Federal Rural de Pernambuco; 2012. 68 p.

8. Dantas-Torres F, Brito MEF, Brandão-Filho SP. Seroepidemiological survey on canine leishmaniasis among dogs from an urban area of Brazil. Vet Parasitol 2006; 140:54-60.

9. Sergent EE, Lombard J, Quilichini M. La Leishmaniose à Alger. Infection simultanée d'un enfant, d'un chien et d'un chat dans le même habitacion. Bullet Soc Pathol Exot 1912; 5:93-98.

10. Nasereddin A, Salant H, Abdeen Z. Feline leishmaniasis in Jerusalem: serological investigation. Vet Parasitol 2008; 158:364-369.

11. Poli A, Abramo F, Barsotti P, Leva S, Gramiccia M, Ludovisi A, et al. Feline leishmaniasis due to Leishmania infantum in Italy. Vet Parasitol 2002; 106 : 181-191.

12. Albuquerque AR. Aspectos epidemiológicos, clínicos e de diagnóstico em cães (Canis familiares) naturalmente infectados por Leishmania (Leishmania) chagasi. [Dissertation]. [Recife]: Universidade Federal Rural de Pernambuco; $2006.59 \mathrm{p}$.

13. Tabar MD, Altet L, Francino O, Sánchez A, Ferrer L, Roura X. Vector-borne infections in cats: molecular study in Barcelona area (Spain). Vet Parasitol 2008; 151:332-336.

14. Shaw SE, Birtles RJ, Day MJ. Arthropod-transmitted infectious diseases of cats. J Fel Med Surg 2001; 3:193-209.

15. Portús M, Gállego M, Riera C, Aisa M. Wild and domestic mammals in the life cycle of Leishmania infantum in Southwest Europe. A literature review and studies performed in Catalonia (Spain). Rev Iberica Parasitol $2002 ; 62: 72-76$ 